\title{
Thyroid dysfunctions and renal status: implications in hyponatremia
}

\author{
Sibasish Sahoo', Suprava Patel ${ }^{2}$, Anirban Ganguly', Rachita Nanda ${ }^{3}$, Eli Mohapatra ${ }^{4}$ \\ ${ }^{1}$ Senior Resident, ${ }^{2}$ Assistant Professor, ${ }^{3}$ Associate Professor, ${ }^{4}$ Professor, Department of Biochemistry, AlIMS, Raipur, \\ Chhattisgarh, India
}

Background: Hypothyroidism is a common endocrine disorder which has been linked to the development of hyponatremia. However, the data supporting the development of hyponatremia is inadequate and confusing. Aims and Objectives: Therefore this study was conducted to investigate an association between hypothyroidism and hyponatremia and to correlate it with other related parameters like renal function status. Materials and Methods: Retrospective analysis of laboratory records of one hundred fifty individuals with TSH level above the normal served as cases and one hundred fifty one individuals with normal TSH served as controls. Results: Hyponatremia( $<135 \mathrm{mEq} / \mathrm{L}$ ) was observed in only twenty-one percent of cases of hypothyroidism. Although patients of hypothyroidism had a significantly lower sodium levels than controls, this was not evident with severity of disease. A high creatinine level evident in the overt cases did not affect the sodium level, although the chloride level was reduced. Conclusion: The present study showed that hyponatremia is not commonly associated with hypothyroidism and screening for hyponatremia is not essential in such patients.

Access this article online Website:

http://nepjol.info/index.php/AJMS DOI: 10.3126/ajms.v8i4.17279

E-ISSN: 2091-0576

P-ISSN: 2467-9100

Key words: Hypothyroidism, Hyponatremia, eGFR, Creatinine

\section{INTRODUCTION}

Measurement of electrolytes is a common diagnostic procedure using ion selective electrodes performed in a clinical chemistry laboratory. Electrolyte homeostasis is regulated by hormones such as antidiuretic hormones, aldosterone and thyroid hormones. Hyponatremia is the most common electrolyte abnormality and to evaluate its underlying cause is often questionable. ${ }^{1}$ All these require extensive laboratory investigations and clinical correlations. The interpretation of these values is somewhat meaningless without analysis of the clinical history and is often impossible without parallel measurements of renal function. Alterations of thyroid hormone, particularly hypothyroidism has historically been linked to the development of hyponatremia. However, though there is evidence to suggest that short term uncomplicated hypothyroidism, can result in reduction in glomerular filtration rate(GFR) and subsequent increase in serum creatinine, ${ }^{2,3}$ the data supporting the development of hyponatremia in this setting is limited and confusing. Moreover, the link between hypothyroidism and hyponatremia as mentioned in standard text books of internal medicine needs to be re-established due to the conflicting sets of previously published data. ${ }^{4}$

The current study was therefore conducted to investigate the association between hypothyroidism and the occurrence of hyponatremia and also to establish if there was any correlation between the severity of hypothyroidism with electrolytes and other renal parameters.

\section{MATERIALS AND METHODS}

Retrograde data analysis was done after screening of laboratory records of samples which were assayed for TSH in the clinical biochemistry lab between December 2015 to March 2017.

All demographic details and other clinical investigations like plasma glucose, renal function tests, which included urea, creatinine, and electrolytes like sodium, potassium 
and chloride were noted from records. Calculated parameters included estimated glomerular filtration rate (eGFR) by Cockckroft and Gault ${ }^{5}$ and serum osmolality. ${ }^{6}$ Data of patients who had elevated TSH levels without taking any medications were included as cases. Data of patients who had come to the hospital for other ailments without hypothyroidism, but had their TSH investigated, which was found to be normal served as controls. Data from a total of 301 samples was collected of which 151 were age and sex matched euthyroid individuals and the rest 150 samples had serum TSH above the normal limits. The cases were further divided into three subgroups ${ }^{7}$ (Figure 1) namely,

i) Mildly high or subclinical hypothyroidism $(4-10 \mu \mathrm{IU} / \mathrm{L})$ -Group I

ii) Moderately high TSH (10 - $75 \mu \mathrm{IU} / \mathrm{L})-$ Group II and

iii) Very high TSH or overt hypothyroidism $(>75 \mu \mathrm{IU} / \mathrm{L})$ -Group III.

TSH was measured by electrochemiluminiscence immunoassay (Cobas e411) and electrolyte analysis was measured by direct ion selective electrodes (Combi Line electrolyte analyser). Fasting plasma glucose (FPG), serum urea and creatinine, were estimated in clinical chemistry autoanalyser (Biosystem BA400) using standard protocol. Hyponatremia was defined as serum sodium concentration less than $135 \mathrm{mEq} / \mathrm{L}$.

\section{Statistical analysis}

Statistical analysis was carried by Graph pad prism 5 software. Student t test was performed to compare parameters between the euthyroid group and the hypothyroid population. Analysis between the control euthyroid group and the three sub groups of hypothyroid subjects was done using one way ANOVA. Correlation analysis using regression was done between electrolytes and

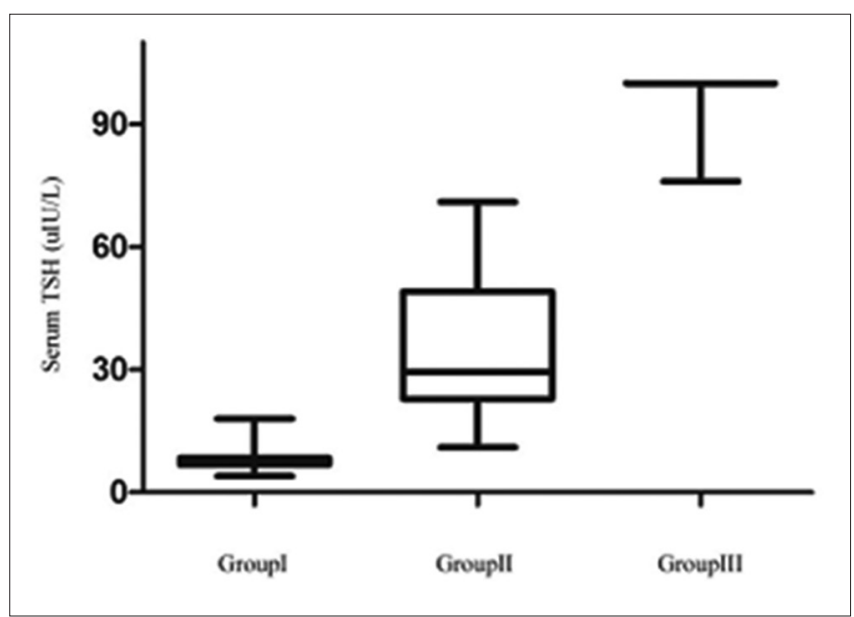

Figure 1: Box plot graph of serum TSH in the stratified hypothyroid population renal parameters with serum TSH. The p-value of $<0.05$ was accounted for statistically significant.

\section{RESULTS AND DISCUSSION}

Table 1 depicted the demographic and biochemical investigations(measured and calculated) in the study population. With $62 \%$ of the patients being females, the mean age of the hypothyroid patients was $39.6 \pm 11.9$ years.

The mean values of FPG in all the three groups of hypothyroidism were within the normal clinical limits. However the glucose values were found to be significantly high in hypothyroid cases $(98 \pm 18 \mathrm{mg} / \mathrm{dl})$ than in the euthyroid population $(84 \pm 12 \mathrm{mg} / \mathrm{dl})$. The role of TSH on glucose metabolism is still under debate. Studies have reported increased insulin resistance ${ }^{8,9,10}$ in hypothyroidism while others have shown decreased insulin resistance ${ }^{11,12}$ or no change..$^{13}$ The reason hypothesized for increased resistance is that peripheral muscles become less responsive in a state of hypothyroidism. Although not properly explained a possible role of poor synchronization of leptin has been also implicated. ${ }^{10}$

The most common parameter on renal function, serum urea, showed a marginal non significant increase in hypothyroid patients, while serum creatinine showed a significant rise in hypothyroidism patients. However, both these values were within the normal reference range. Such elevation of urea and creatinine levels in hypothyroidism have been shown previously by few researchers, ${ }^{14,15}$ thereby concluding that renal function may be altered and should be regularly monitored in hypothyroid patients.

Serum sodium and chloride documented a significant decline in hypothyroid patients, however the serum potassium showed no change from euthyroid persons. The mean sodium level in hypothyroid cases was in the normal range but few authors have documented presence of hyponatremia in patients of hypothyroidism. ${ }^{16-19}$ The eGFR although normal, was significantly lowered in hypothyroid patients, and is a reflection of serum creatinine. ${ }^{20} \mathrm{~A}$ similar change was also observed in osmolality in hypothyroid patients.

To compare the biochemical parameters of the stratified hypothyroid subjects, one way ANOVA was used which is shown in Table 2. As observed the plasma glucose level shows a gradual significant rise with increase in state of hypothyroidism. Hypothyroidism in all degrees whether subclinical, moderately elevated or overt have been associated with disorders of glucose metabolism. ${ }^{21,22}$ However, the exact mechanism connecting hypothyroidism 
Table 1: Demographic and biochemical parameters (mean \pm SD) of controls and cases

\begin{tabular}{lccc}
\hline Parameters & Euthyroid $(\mathbf{n}=\mathbf{1 5 1})$ & Hypothyroid $(\mathbf{n = 1 5 0})$ & p value \\
\hline Age $($ Years) & $39 \pm 13$ & $39.6 \pm 11.9$ & 0.67 \\
Male: Female(\%) & $97: 54(64.2: 35.8)$ & $93: 57(62: 38)$ & 0.84 \\
Fasting plasma glucose $(\mathrm{mg} / \mathrm{dl})$ & $84 \pm 12$ & $98 \pm 18$ & 0.0001 \\
Serum Urea $(\mathrm{mg} / \mathrm{dl})$ & $21 \pm 5.8$ & $24.06 \pm 9.3$ & 0.08 \\
Serum Creatinine $(\mathrm{mg} / \mathrm{dl})$ & $0.78 \pm 0.2$ & $0.85 \pm 0.2$ & 0.002 \\
Serum Sodium $(\mathrm{mEq} / \mathrm{L})$ & $139 \pm 3.4$ & $137.8 \pm 4.8$ & 0.01 \\
Serum Potassium $(\mathrm{mEq} / \mathrm{L})$ & $4.6 \pm 0.4$ & $4.7 \pm 0.5$ & 0.80 \\
Serum Chloride $(\mathrm{mEq} / \mathrm{L})$ & $106.2 \pm 3.7$ & $105.3 \pm 3.6$ & 0.03 \\
eGRF ( ml/min) & $116 \pm 36.4$ & $103 \pm 24.3$ & 0.001 \\
Serum Osmolality (mOsm/kg) & $287 \pm 6.6$ & $284.7 \pm 9.5$ & 0.01 \\
\hline
\end{tabular}

\begin{tabular}{|c|c|c|c|c|}
\hline TSH Range ( $\mu \mathrm{IU} / \mathrm{L})$ & $\begin{array}{c}\text { Group I } \\
4-10(n=50)\end{array}$ & $\begin{array}{c}\text { Group II } \\
10-75(n=50)\end{array}$ & $\begin{array}{c}\text { Group } \\
I I I>75(n=50)\end{array}$ & $\mathrm{p}$ value \\
\hline \multicolumn{5}{|l|}{ Parameters } \\
\hline Fasting plasma glucose (mg/dl) & $91.5 \pm 10.53$ & $93.3 \pm 10.01$ & $108.3 \pm 24.07^{*}$ & $<0.0001$ \\
\hline Serum Urea $(\mathrm{mg} / \mathrm{dl})$ & $21.7 \pm 7.5$ & $22.5 \pm 6.7$ & $23.50 \pm 11.75$ & 0.77 \\
\hline Serum Creatinine $(\mathrm{mg} / \mathrm{dl})^{*}$ & $0.74 \pm 0.12$ & $0.78 \pm 0.13$ & $0.88 \pm 0.21^{*}$ & 0.004 \\
\hline Serum Sodium (mEq/L) & $138.1 \pm 4.8$ & $137.7 \pm 3.7$ & $136.6 \pm 5.5$ & 0.28 \\
\hline Serum Potassium (mEq/L) & $4.5 \pm 0.44$ & $4.54 \pm 0.34$ & $4.68 \pm 0.58$ & 0.78 \\
\hline Serum Chloride $(\mathrm{mEq} / \mathrm{L})^{*}$ & $106.2 \pm 3.5$ & $106.2 \pm 2.56$ & $104.4 \pm 4.09^{*}$ & $<0.01$ \\
\hline eGRF (ml/min) & $108.2 \pm 3.26$ & $107.8 \pm 25.31$ & $105.6 \pm 30.9$ & 0.55 \\
\hline Serum Osmolality (mOsm/kg) & $284.9 \pm 9.39$ & $283.8 \pm 7.8$ & $283.1 \pm 11.1$ & 0.69 \\
\hline
\end{tabular}

to insulin resistance is still unclear. In these patients, the change was significant $(p<0.01)$ in the overt group in comparison with the subclinical and moderately hypothyroid group. A gradual rise in serum urea and serum creatinine was observed along with a parallel rise in TSH levels in patients of hypothyroidism. The reduction in renal blood flow and GFR could be responsible for reduced clearance of urea and creatinine and thus its elevation. ${ }^{23}$ The serum creatinine in overt hypothyroidism was significantly elevated $(p<0.01)$ as compared to the other two groups of patients.

Apart from serum chloride, which was significantly lowered in overt group in comparison to the other two groups, there was no significant change in serum sodium and potassium. Although it has been shown that hyponatremia was more common in patients with impaired renal functions, ${ }^{2,14}$ our observation was that even with declining renal function the change in sodium level was not significant. Thirty-two $(21.3 \%)$ cases had serum sodium less than $135 \mathrm{mEq} / \mathrm{L}$, the value defined for hyponatremia, however there was no case with sodium less than $120 \mathrm{mEq} / \mathrm{L}$. Sixteen(50\%) of the hyponatremic patients were in the group of overt hypothyroidism. A Fischer's exact test showed no significant difference between the three groups in proportions of sample that had a serum sodium below $135 \mathrm{mEq} / \mathrm{L}(\mathrm{p}=0.06)$. A linear regression between the hypothyroid patients $(n=32)$ and creatinine documented no association between these parameters $\left(R^{2}=0.028\right.$, $\mathrm{p}=0.35$ ). Thyroid dysfunction has been shown to cause remarkable changes in glomerular and tubular functions resulting in poor electrolyte and water homeostasis. ${ }^{24}$ The increased systemic vascular resistance, reduced GFR and renal flood flow associated with hypothyroidism results in reduced excretion of water by the kidneys. ${ }^{25}$ However, this was not the case in our study population as the eGFR and osmolality were insignificantly changed. However, although the sodium declined, because of low osmolality, the chloride was reduced much in degree.

The correlation coefficient as depicted in Table 3, shows a negative correlation of TSH only with sodium, whereas a positive correlation with potassium, chloride, eGFR and osmolality.

Regression analysis after logarithmic transformation of TSH revealed, no significant correlation with serum sodium concentration $\left(\mathrm{R}^{2}=0.009\right)$ (Figure 2 ) or chloride concentration $\left(R^{2}=0.089\right)$. Studies where an association between hypothyroidism and sodium have been described are generally in myxedemic population or in acute or chronic illness and hospitalized patients. ${ }^{26,27}$ Although the reason of hyponatremia in myxedemic coma is multifactorial, renal tubular function gets affected due to decline in GFR to cause hyponatremia. ${ }^{28}$ A finding similar to ours have been documented by authors who 


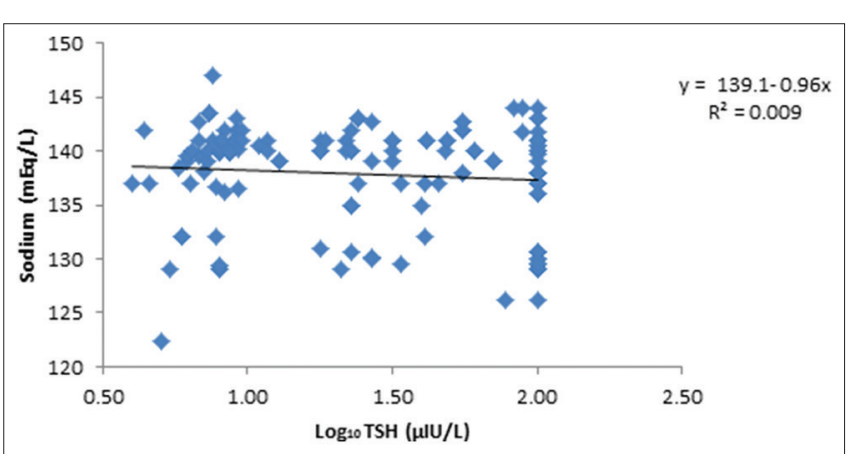

Figure 2: Linear regression of log transformed TSH with serum sodium in hypothyroid patients

Table 3: Correlation coefficient of electrolytes
and calculated parameters in patients of
hypothyroidism
\begin{tabular}{lccccc} 
Parameters & Sodium & Potassium & Chloride & eGFR & Osmolality \\
\hline TSH & -0.13 & 0.10 & 0.44 & 0.25 & 0.06 \\
\hline
\end{tabular}

found weak or no relationship between hypothyroidism and hyponatremia. ${ }^{17,29-31}$

The negative correlation between serum sodium levels and serum TSH was not statistically significant, the level of sodium were not clinically significant in any group and did not necessitate any treatment. Although a small number $(21 \%)$, the reason of hyponatremia could not be elicited as the study was an analysis of database. The biggest limitation of this study was that it was a retrospective analysis, and many other clinical parameters could not be collected for laboratory records which could have been correlated. Because the population under study was less than 40 years, electrolyte homeostasis may have been maintained inherently by the body even with alteration in TSH level. Therefore while choosing population different age groups must be studied.

\section{CONCLUSION}

This study found that although sodium levels declined, hyponatremia was not a prominent finding of hypothyroidism. With a lot of cross sectional studies being published what is now needed is a systematic review with meta-analysis for a satisfactory appreciation of hyponatremia in hypothyroidism.

\section{REFERENCES}

1. Abuzaid AS and Birch N. The Controversies of Hyponatraemia in Hypothyroidism. Sultan Qaboos Univ Med J 2015; 15(2): e207-e212.

2. Baajafer FS, Hammami MM and Mohamed GE. Prevalence and severity of hyponatremia and hypercreatininemia in short-term uncomplicated hypothyroidism. J Endocrinol Investig 1999; 22:35-39.

3. Montenegro J, Gonzalez O, Saracho R, Aguirre R, Gonzalez $\mathrm{O}$ and Martinez I. Changes in renal function in primary hypothyroidism. Am J Kidney Dis 1996; 27:195-198.

4. Croal BL, Blake AM, Johnston J, Glen AC and O'Reilly DS. Absence of relation between hyponatraemia and hypothyroidism. Lancet 1997; 350:1402.

5. Cockcroft DW and Gault MH. Prediction of creatinine clearance from serum creatinine. Nephron 1976; 16(1):31-41.

6. Purssell RA, Pudek M, Brubacher $J$ and Abu-Laban RB. Derivation and validation of a formula to calculate the contribution of ethanol to the osmolal gap. Ann Emerg Med 2001;38(6):653-659.

7. Fatourechi V. Subclinical Hypothyroidism: An Update for Primary Care Physicians Mayo Clin Proc 2009; 84(1):65-71.

8. Dimitriadis G, Parry-Billings M, Bevan S, Leighton B, Krause U, Piva $T$, et al. The effects of insulin on transport and metabolism of glucose in skeletal muscle from hyperthyroid and hypothyroid rats. Eur J Clin Invest 1997; 27(6):475-483.

9. Chaoxun Wang. The Relationship between Type 2 Diabetes Mellitus and Related Thyroid Diseases. Journal of Diabetes Research 2013; vol. 2013, Article ID 390534, 9 pages, 2013.

10. Cettour-Rose P, Theander-Carrillo C, Asensio C, Klein M, Visser TJ, Burger AG, et al. Hypothyroidism in rats decreases peripheral glucose utilisation, a defect partially corrected by central leptin infusion. Diabetologia 2005; 48(4):624-633.

11. Stanicka S, Vondra K, Pelikanova T, Vlcek P, Hill M and Zamrazil V. Insulin sensitivity and counter-regulatory hormones in hypothyroidism and during thyroid hormone replacement therapy. Clin Chem Lab Med 2005; 43:715e20.

12. Rochon C, Tauveron I, Dejax C, Benoit P, Capitan P, Fabricio A, et al. Response of glucose disposal to hyperinsulinaemia in human hypothyroidism and hyperthyroidism. Clin Sci 2003; 104:7-15.

13. Owecki M, Nikisch $E$ and Sowinski J. Hypothyroidism has no impact on insulin sensitivity assessed with HOMA-IR in totally thyroidectomized patients. Acta Clin Belg 2006;61: 69e73.

14. Saini V, Yadav A, Arora MK, Arora S, Singh R and Bhattacharjee J. Correlation of creatinine with TSH levels in overt hypothyroidism - A requirement for monitoring of renal function in hypothyroid patients? Clinical Biochemistry 2012;45(3):212-214.

15. van Hoek I and Daminet S. Interactions between thyroid and kidney function in pathological conditions of these organs: A review. Gen Comp Endocrinol 2009; 160(3):205-215.

16. Schwarz C, Leichtle AB, Arampatzis S, Fiedler GM, Zimmermann $\mathrm{H}$, Exadaktylos AK et al. Thyroid function and serum electrolytes: does an association really exist? Swiss Med Wkly 2012;142:w13669.

17. Warner MH, Holding $S$ and Kilpatrick ES. The effect of newly diagnosed hypothyroidism on serum sodium concentrations: a retrospective study. Clin Endocrinol (Oxf) 2006; 64(5):598-599.

18. Liamis G, Milionis $\mathrm{HJ}$ and Elisaf M. Endocrine disorders: causes of hyponatremia not to neglect. Ann Med 2011; 43(3):179-187.

19. Milionis HJ, Liamis GL and Elisaf MS. The hyponatremic patient: a systematic approach to laboratory diagnosis. CMAJ 2002;166(8):1056-1062.

20. Asvold BO, Bjøro $T$ and Vatten LJ. Association of thyroid function with estimated glomerular filtration rate in a population-based study: the HUNT study. Eur J Endocrinol 2011;164(1):101-105.

21. Dimitriadis G, Baker B, Marsh H, Mandarino L, Rizza R, Bergman R, et al. Effect of thyroid hormone excess on action, 
secretion, and metabolism of insulin in humans. Am J Physiol 1985; 248(5Pt 1): E593-E601.

22. Dimitriadis G, Maratou E, Boutati E, Kollias A, Tsegka K, Alevizaki $M$, et al. IGF-I increases the recruitment of GLUT4 and GLUT3 glucose transporters on cell surface in hyperthyroidism. Eur J Endocrinol 2008; 158(3):361-366.

23. Lippi G, Montagnana M, Targher G, Salvagno GL and Guidi GC Relationship between thyroid status and renal function in a general population of unselected out patients. Clin Biochem 2008;41(7-8):625-627.

24. Iglesias $\mathrm{P}$ and Díez JJ, Thyroid dysfunction and kidney disease. Eur J Endocrinol 2009; 160(4):503-515.

25. Montenegro J, Gonzalez O, Saracho R, Aguirre R, Gonzalez O and Martinez I. Changes in Renal Function in Primary Hypothyroidism. Am J Kidney Dis 1996; 27:195-198.
26. Derubertis FR, Michelis MF, Bloom ME, Mintz DH, Field JB and Davis BB. Impaired water excretion in myxedema. Am J Med 1971; 51:41-53.

27. Upadhyay A, Jaber BL and Madias NE. Incidence and prevalence of hyponatremia. Am J Med 2006;119 (Suppl. S1):30-35.

28. Pantalone KM and Hatipoglu BA. Hyponatremia and the Thyroid: Causality or Association? J. Clin. Med 2015; 4(1): 32-36.

29. Croal BL, Blake AM, Johnston J, Glen AC and O'Reilly DS. Absence of Relation between Hyponatraemia and Hypothyroidism. Lancet 1997; 350:1402.

30. Tran HA and Petrovsky N. Hypothyroidism and Hyponatraemia in the Hospital Setting. Pathology 2005;37:179-181.

31. Hunze J, Jsselstijn L, Wulkan RW and van Alphen AM. Does Hypothyroidism Cause Hyponatremia? Health 2014; 6: $1453-1458$.

\section{Authors Contribution:}

SS- Collected data, review literature manuscript preparation, statistical analysis and interpretation; SP - Preparing first draft of manuscript, statistical analysis and interpretation; AG - Collected data, manuscript preparation, statistical analysis and interpretation; RN - Concept and design of study, interpretation, helped in preparing first draft of manuscript and critical revision of manuscript; EM - Interpretation, helped in preparing first draft of manuscript and critical revision of manuscript.

\section{Work attributed to:}

Department of Biochemistry, AIIMS, Raipur, Chhattisgarh

Orcid ID:

Dr. Sibasish Sahoo: http://orcid.org/0000-0002-0615-2086

Dr. Suprava Patel:i http://orcid.org/0000-0002-7449-1354

Dr. Anirban Ganguly: (i) http://orcid.org/0000-0002-5007-7116

Dr. Rachita Nanda: http://orcid.org/0000-0002-6808-6176

Dr. Eli Mohapatra: http://orcid.org/0000-0002-3339-4654

Source of Support: None. Conflict of interest: None declared. 